Journal of Law \& Social Studies (JLSS)

Volume 3, Issue 1, pp 67-72

www.advancelrf.org

\title{
Pakistan - United States of America Relations: Impediments and way forward
}

\author{
Faisal Ameer Marwat \\ MPhil Scholar \\ University of Baluchistan, Quetta \\ Email: fomee11170@gmail.com
}

\begin{abstract}
During the past seven decades, the relations among America and Pakistan have seen such a significant number of ups and downs. Hindered by different commitment, solid and particular irritation, both of states have attempted to impact each other, but have been unsuccessful at significant number of stages. Pakistan once saw, as the most associated partner when fits to United States of America interests in 50s, twisted hooked on utmost endorsed companion of America in 90s. The centralization of relations fluctuated from one perilous to that of totally overlooking the different as in 1971, to that of critical activity as was seen following the intrusion of Afghanistan by the Soviets in December 1979 and during the war on psychological warfare after 9/11 assaults, which totally changed the image of the relations. Meanwhile the occasions of 9/11, Pakistan devours embraced a proactive and realistic methodology in its isolated relations that helped nation to organize a discretionary rebound at provincial and all-inclusive echelons. Pakistan had option towards successfully modification post-9/11 difficulties hooked on situations and thus become cutting edge worldwide actions against psychological combat. Global network properly recognized commitment in contradiction of anxiety mongering; activities make stable local complaint by preliminary procedures towards improved relations by way of India and Afghanistan. Following finish of the Taliban system in Afghanistan and an adjustment in Pakistan's Afghan approach, a significant prevention in improving relations with Russia and the Central Asian states has been evacuated and there are solid indications of progress in respective relations.
\end{abstract}

Key words: Pakistan, United States of America, War on Terror, Impediment, way forward

\section{Introduction}

The America and Pakistan built up strategic relationship in 1947. USA settled after providing monetary and military help to Pakistan and the later cooperation in the CENTO formerly known as Baghdad Pact and SEATO strengthened relations between the two countries (Gordievsky, 1984). Instead of its military help to Pakistan, in hours of need during 1965 and 1971 war US proved itself as an unreliable partner. Despite the fact that US provided military help to every nation stressed in the contention, the US aid and help and Pakistan received proved to be counter-productive for Pakistan (Wriggins, 1984).

The historic framework of Pak-US relations has seen many ups and downs; there have been the periods of extraordinary assurance and antagonism. Every charm remains portrayed by stirring American hollow of Pakistan's key connotation. By way of representative, furthermost enormous remained a definitive three interchanges that occurred one underneath Reagan supervision when enemy of Soviet partnership used to be made with Pakistan. US have been investing in Pakistan based on the fact that it has been a major contributor in creating conflicting situation inside Pakistan. Example of every one incantation expresses towards the aforementioned adjusting circumstances with United States of America and the contemporary circumstances addresses whether America was scenery obtainable in the direction of authentic cyclic way (Ziring, 1982). 
Both nations have thrived in the periods of global tensions, in the early period of 1950 and towards 1980 and till the 9/11 incident, which had brought harshness in conditions of reconciliation. Pakistan and the Unites States of America faced tremendous ups and down which left multiple questions to be answered. During the Kennedy, Johnson, and Carter administrations there have been many significant variations. However, the Clinton administration had showed much more interest in Pakistan than the previous ones (Rizvi, 1971: Khan, 1961).

Pakistan and US collaboration was resulted in the disintegration of Russia in the wake of Afghan war of 1979 or "Afghan Jihad". American lost their most trusted ally, shah of Iran, in and it threatened the US regional interests so US wanted to counter emerging Russian hegemony with the help of Pakistan at that time. Both US and Pakistan were of the opinion that Russian invasion of Afghanistan was a demonstration of Russian expansionist policy in the region so the interests of both powers were converged on this issue (Akbar, 2015). Pakistan's support to United States of America in War on Terror by accepting all conditions such as providing air bases, logistic support and intelligence sharing to United States. Pakistan withdrew its unprecedented support from Taliban in the wake of this war on American pressure and took famous "U-Turn" in its Afghan Policy (Akbar, 2015).

United State of America is also worried due to rise of China particularly due to China Pakistan Economic Corridor (CPEC) and role of Pakistan in it (Mushtaq, 2019). On one hand, it will strengthen Pakistan's economy whereas on the other hand it will give an opportunity to Pakistan in consolidation China's political support to Pakistan at international platform. The American Strategic objectives in the region have also threatened by this partnership. Indian is also an important external factor that is affecting the Pak-US relations. Although Pakistan has supported United States whole heartedly in the War against Terrorism specially in Afghanistan, India is considered as an important element by United States due to its help particularly in Afghanistan after the toppling of Taliban regime since day first (Tariq et.al., 2019)

Harsh, 2000 in his hypothesis demonstrates that the Pakistan-United States connection advanced during 1947 to 1958. Further, it is noticed since commencement of Pakistan, the focal vulnerability observation persisted India. All the leaders of Pakistan since establishing form Quaid-e-Azam to Zia, valued assistance from America. Along these lines Pakistan amalgamated Western encampment but it has remained the major beneficiary of the United States economic and military aid.

Broad writing of worldwide relations focuses on multidimensional elements, components and procedures of advancing relations between countries. Be that as it may, network of country works inside efficient and entire interfacing inside lawful structure which concerned different stages, social, social, monetary and political stage. This system is coordinated by various hypotheses and proof from past literary works. This hypothesis of collaboration stresses on the specific elements of participation inside the legitimate structure, which might be named as affiliation. Affiliation are the most imperative part of worldwide relations, which are exposed to numerous elements and hypotheses that can be ordered as topographical, political and ideological angle.

Different sources have been used, for instance, dispersed reviews, journal articles, news reports and Books in this research article. Basic sources have been guided to get increasingly broad view to the explanation behind Pakistan's enlistment to United States of America bolstered Western understandings and its impacts on Pakistan. Basic data has been assembled through gatherings, understandings, and authority file. Semi-composed individual gatherings were coordinated with analysts, government specialists and surrendered and in organization military work power. In addition, the investigation depends on the hypothesis of alliance to dissect the idea of Pakistan-United States of America's relationship and made proposals to keep up balance in their relations.

Numerous researchers introduced their hypotheses to examine the elements of relationship between countries. The noteworthy factor in controlling universal governmental issues is national enthusiasm of some random express that closes into constant rivalry among states. States are compelled by a solemn obligation to give insurance to their residents and guarantee security. In this way, happening world juncture it is seen countries taking a stab at power, upgrading military structure enlightening the financial limit of state against others (Ahmed, 1999).

Ahmad (1988) gives the origin of worldwide governmental issues, the main possible objective of a state has been to build their capacity for ensuring its security. While making sure about national interest, countries even intersection military affiliation, however, all countries take part in taking military on board in many decisions particularly in matters of security. Affiliation is utilized by both, the more fragile nations and more grounded nations to look for and provide food to the people of their countries for the national interests. US welcomed Pakistan to hold Cold War resistance relationship subsequently they had enthusiasm towards oblige although Pakistan partaken vanished along with own advantage, consequently twofold nations go hooked on coalition if their advantage concur. 
In any case, Alavi, 1988 clash is the cardinal factor that advances affiliation framework in worldwide legislative issues. In any case, different components assume their jobs also however they can't be put on a similar hold. The US can continue its relationship with India, but it must find ways to engage with India in a manner that does not further undermine the Pakistan-US relationship. Pakistan's growing reliance on China could also be better managed if Pakistan can identify means to simultaneously develop a more stable partnership with the US based on mutual national interests.

This is a conspicuous truth that lopsided affiliation has their foundations toward struggle; in any case such affiliation is not doable for both the partners. Affiliation dependent on clashes might be delegated residential, local and worldwide. Local affiliation include outsider from outside for adding validity to their activities to turn into a piece of global framework. In lopsided affiliation both the partners appreciate confined advantages by common sharing of assets. Ahmed (1999) sorted the relationship as adjusting affiliation and show affiliation. Moreover, the adjusting affiliation is cautious while show affiliation is forceful in nature.

The greater part of the more vulnerable states favor show since they add more to the forceful danger by lining up with it. The end of Cold-War has developed extraordinary changes in the idea of universal relations that additionally adjusted the elements of contention and participation consequently changing the utility and United States of America of partner hypothesis, which drove the issue to be talked about the alternate points of view which are as follow:

- The change in the elements of universal legislative issues modified the affiliation design between the two states.

- With the change of worldwide governmental issues the specially appointed affiliation has gotten increasingly important.

- After increase of psychological militant exercises the idea of affiliation endured to a huge broaden.

- The expansion of atomic artilleries devours preferential requirements relationship aimed at countrywide.

- With the quickly developing globalization pertinence idea of affiliation improved.

- Through difference in foe subsequently finish of cold-war states requirements aimed at affiliation reduced.

- Descending slant guard spending tolerates beneficial outcomes on partner hypothesis (Pirzada, 2003; Paul, 2002).

The whole history of affiliation connection among Pakistan and US shows consistently advanced nationwide intrigue and chose standards for Pakistan especially in and subsequently 9/11 when the United States of America went about as a hegemon as opposed to an accomplice. Be that as it may, the consistency in the two accomplice's danger recognition at local and universal level can't be neglected. Post 9/11 situation strict combativeness in Afghanistan nearby neighbor Pakistan presented danger worldwide security. Thusly, battle in contradiction of fear mongering turns into the distinctive attributes of security relations among Pakistan and US. Above multiple theories conceptual framework is drawn which is s follow:

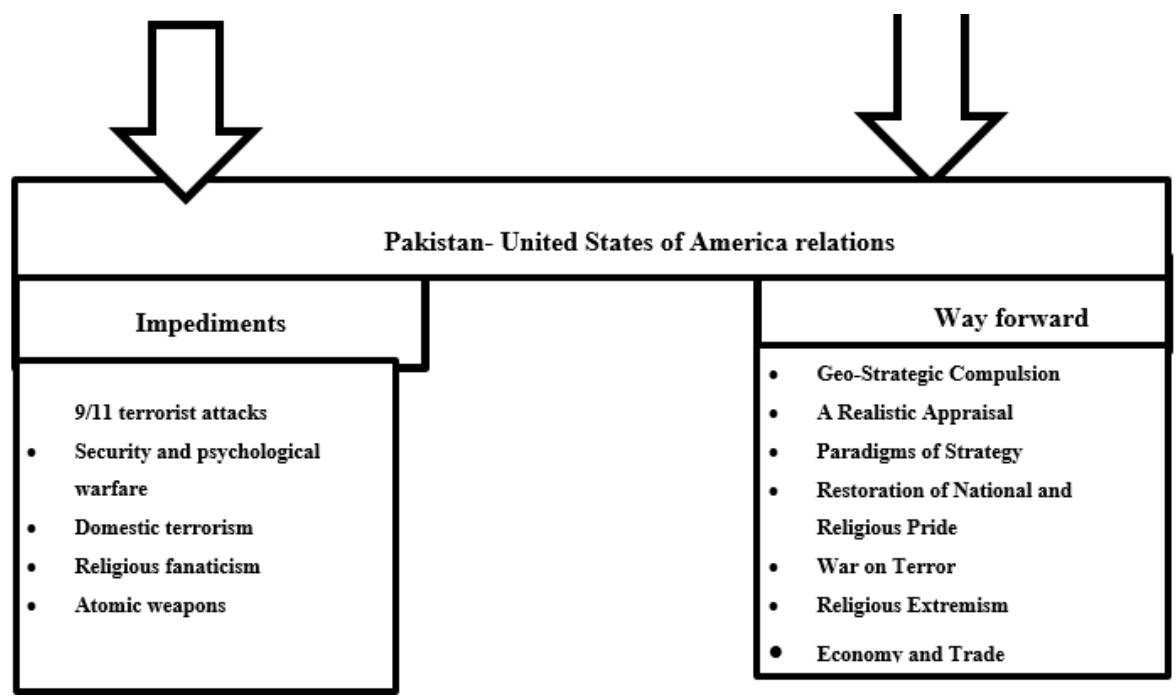


The above drawn theoretical system is mirroring that, why relations between Pakistan and US keep on fluctuating. Numerous specialists have analyzed how and why the connection among two countries have confronted such difficulties, so a large portion of them have shown previously mentioned impediments and some of path forward, so as to recuperate the current relations. By one way or the other, the lacking of trust and enthusiasm of revamping are strong indicators in the relations among the two countries.

The bilateral relations among both states have seen improvement during War against Terrorism due to convergence of interests and partnership in thia war. Subsequent to concerning various research paper it tends to be brought into light that inappropriate methods for international strategy has diverted the companionship way here is the exploration Gap of this investigation which may assist with revamping and gloat up the relations among the two countries.

\section{Objective of the study}

The investigation centers around the underneath objectives;

1. To look at the variables of Pakistan-US Relations.

2. To break down the impact of Pakistan's remote relations and domestic governmental issues.

3. To assess the upsides and downsides of Pak-US relations.

4. To break down the future possibilities of Pakistan-US relations.

This exploration limits the relations of Pakistan and United States of America. This investigation incorporates different strides of the relationship, for example, political social and monetary help.

The examination means to distinguish the obstacles and approach to mend the issues of investigation and further clear the created questions. In any case, after the freedom of 1947 United States of America and Pakistan has developed strategic relationship. The fundamental subject of the connection depended on the shared thought. The United States of America consented to give military and social financial and political help.

The conciliatory relationship of the two countries faces a few ups and down, subsequently only Pakistan pays the expense. After the 9/11 the relations were bad as a result of considering Pakistan as a fear-based oppressor country and makers of psychological warfare, and afterward Pakistan has power to confront the charge of psychological militant financing nation, which radically brought a tremendous hole between the two countries.

After the 9/11 the relations of both countries never engaged in a decent connection. The primary purpose of this investigation is to complete understanding of the issues which obstacles among Pakistan and United States of America and give better arrangements and future if this relationship.

Post World War II US-USSR created as the most powerful states of that time. A couple of states joined communist block while a couple of states joined the industrialist Capitalist block. Pakistan joined the Capitalist Block to safeguard its national interests and to get political and budgetary help. The seventy years of relationship shows that Pak-US relations has been a story of cooperation and competition, convergence and divergence of interests on different points of history.

In the changing overall condition, US have been expecting activity of starting and deactivating worldwide events. Of course Pakistan is standing up to number of troubles inside and remotely. This examination has had the option to be given material data about the Pakistan-United States relations. The drifting relationship of Pakistan-Untied States and its effect on the world is a serious concern for global politics because these bilateral relations among both states do have the capacity to change the dynamics of international political scenario in many contexts due to their respective positions.

\section{Way Forward: A Realistic Appraisal}

Right now, it has been center around the conceivable treatment of the relations, that the international strategies of the two countries. The mistrust among both states can lead towards further deterioration in bilateral relations among both states. Withdrawal from Afghanistan is a key point of history and both states want to solve this issue not only amicably but also as soon as possible due to multiple reasons. The cooperation among both states can materialize this step otherwise it will take long time and will create further complexities for both states in future. 
What Pakistan must recognize is that the current set up is a marriage of settlement and this is neither as for theory, nor on an idea of association; yet simply it is like the case in all inclusive associations, it relies upon blending of interests. Likewise, the United States interests are the annulling factor. There is no basis in doing combating reality and no purpose behind uneven unfriendly relations with America.

The relationship suits our inclinations also, and it would miss one progressively possibility in the event that it by one way or another happened to let this one sneak past. Pakistan needs to endeavor for a noteworthy and important responsibility with US what's extent that this would be possible, to improve contact and grow its base so as to remain a critical player in the region similarly as the Muslim Ummah. What Pakistan must be careful about is not to be put all the speculations tied up on one place and be gotten ill-equipped.

This is the perfect open door for internal action and association to get quality, and we should profit of this opportunity. While looking for after along these lines, Pakistan should not be egotistical and must work out strategies if the scourge of the war on fear and the statute of pre-emption are highlighted; taking everything into account, a confusion or another scene with linkages to Pakistan isn't out of the area of probability.

With the current condition and how much Pakistan can benefit by this relationship will totally depend upon Pakistan's domestic political quality and on the difference in its state foundations. Pakistan's future course and method must objective reducing own vulnerabilities while gathering most prominent piece of adaptability from those of US. All while, it ought to reasonable and execute competent.

This must transform into a communicated and vivaciously looked for after game plan objective. Pakistan cannot value stately influence without dealing with us. What must be fathomed is that it isn't critical to annoy others in affirmation of this point; while dealing with the US, Pakistan must not view it as an exchange off on its capacity. National regard must be viewed and a positive perception with this effect be made both inside and in the worldwide system.

The capacities of Pakistan's carefulness face and its fundamental examination concerning upsetting American uncertainty of guarantee creating relationship with China. Pakistan must look for after this essential relationship, while gathering benefits by fighting Sino-US interests without irritating in the event that the Indians are dealt with an open field to develop relations.

The contemporary United States position of individual relationship with both Pakistan and India, liberated from each other, is loaded with chance for the Pakistan. The Pakistan would as of now have the option to watch the presence of this in the creating United States of America-India essential relationship. This Influence oversaw by the contemporaneous condition be put to suitable use to disturb and delay this creating interconnection, and to address the standard disproportionateness this is similarly as 'power' the United States of America to empower the Kashmir objectives.

Pakistan must continue with its help to the overall war on fear. In any case, US made esteem have's essential worry' in such way. This similarity of interests must be intentionally controlled to have advantage. The framework must survey inside aftermaths; believe it or not, pre-empt those if possible.

There is no such class in Pakistan, really, this term is a logical inconsistency, and the United States of America be drawn closer to esteem have point of view just as to consent. On the Pakistan part, it ought to unfeelingly discover radicals who execute showings of devotion. The social utility of Madrassas and the push to convey them into the standard are recognized to the Americans and to the world. This is only the misinterpretation in any case Pakistan would endure the most. The out siders affected to the enormous broaden, which is wild neither Pakistan nor United State of America.

Pakistan needs to work with the United States of America on assurance building measures in such way. Without exchanging off case national security and interests, Pakistan ought to be viewed as a reliable nuclear force. It ought to be segregating that US acknowledgment, in numerous others, will frame world supposition; the atomic expansion this need of Pakistan as the neighboring peering toward for the rejoining the nation with its own. In addition, Pakistan has a significant geo-key for the expanding financial movement, and to have a least method for coming to the European nations advertise.

Pakistan must be vocal against the "unconsecrated media surge" fastened against it by the American and western electronic media. This is one of the significant issue where Pakistan and should be not vague. All of Pakistan endeavors are rendered ineffective as the acknowledgment about Pakistan being worked by the media is what people see to be 
substantial. It ought to be associated straightforwardly to the level of have sponsorship to US. Right now, may have a portrayed emergency. All the more decisively, the country's needs to the forefront for it media inclusion, and it can have enormous effect on the western world extraordinarily.

War on Terror Pakistan destroyed their economy and trade similarly as their watchman. US of America should offer Pakistan endowments free intrigue credit or to get to the International Financial Institutions and sorted out a business structure with Pakistan give a lift to their relationship. The bragging up the economy and exchange further purpose such a large number of strain inside Pakistan, this can be demonstrate productive for the two countries. Rather than sanctions, attempt to improve economy.

\section{Conclusion}

The history of Pakistan US relations has always been very interesting. Bilateral relations among both states since the inception of Pakistan are of cooperative and competitive nature. US helped Pakistan only when US wanted to secure its own national interests. Whereas, whenever Pakistan needed the US, its support was lacking. During War on terror both states cooperated in many cases and got success against militant and terrorists. However when their interests were different, both were unable to get their desired results due to mistrust and non-cooperation. The factor of China through CPEC is also affecting the bilateral relations. However, both states must understand that in some cases such as US withdrawal from Afghanistan and Kashmir Issue, a continuous engagement among both states is inevitable.

\section{References}

Ahmad, F. (1988). "Alliances and the Breakup of Pakistan.” Washington: Pakistan Forum,. Middle East Research and Information Project, Vol. 2, No25.

Ahmed, S. (1999). "Pakistan's nuclear weapons program: turning point and nuclear choices. International Security, Vol. 26, No. 4.

Akbar, M. (2015) "Islamisation in Afghanistan and Afghan Jihad: A Critical appriasal”, Al-Adwa, 44:30, 73-90.

Akbar, M. (2015) A Critical Analysis of Pakistan's U-Turn on Aghan Policy After Spetember 11", Pakistan Annual Research Journal, Vol. 51, 122-139.

Alavi, H. (1998).). “Pakistan-US Military Alliance.”. Economic and Political Weekly, , Vol. 33, No. 25.

Gordievsky. (1984 ). "War of Ideology.”. International Security,, Vol. 5, No. 1.

Mushtaq, F. (2019). "Prospects for Pak-China Relations”, Global Political Review, Vol. IV, No IV. 49-58.

Paul, T. V. (2002). "Influence through Arms Transfers: Lessons from the US-Pakistani Relationship." . Asian Survey., 32 , no. 12 .

Pirzada, M. (2003). “Kashmir: Indian Strategic Initiative since 9/11 and Imperative for US Policy in the Region”. , IPRI Journal, , Vol. 11, No. 1 .

Stern, J. ( 2000). “Pakistan"es Jihad Culture.” . “Foreign Affairs, , Vol. 79, No. 6.

Tariq, M., Arif khan and Bakhtiar Khan (2019). "Pakistan’s Security Dilemma with Afghanistan and India", Global Political Review, Vol. IV, No. IV. 70-77.

Wriggins., H. (1984).). Pakistan's Search for a Foreign Policy after the Invasion of Afghanistan. Pacific Affairs, , Vol. 57, No. 2.

Ziring, L. (1982.). “South Asian Tangles \& Triangles.” in Lawrence Ziring (Ed). The Subcontinent in World Politics: India: It's Neighbors \& the Great Powers. . New York: Praeger . 